Special issue: Re-Design Teaching Design

Article

\section{Beyond Discipline: Evolving Design Practice and Design Education in the Twenty-First Century}

Dr Lara Furniss

Lecturer in Performance Design, School of Visual Communication, Birmingham City University, UK; lara.furniss@bcu.ac.uk

Guest Editors: Lohren Deeg, Taylor Metz, Richard Tursky, Ball State University, USA

How to Cite: Furniss, L. 'Beyond Discipline: Evolving Design Practice and Design Education in the Twenty-First Century'. Architecture_MPS 18, 1 (2020): 4.

DOI: https://doi.org/10.14324/111.444.amps.2020v18i1.004.

Submission date: 7 April 2020; Acceptance date: 15 June 2020; Publication date: 2 November 2020

\section{Peer review:}

This article has been peer-reviewed through the journal's standard double-blind peer review, where both the reviewers and authors are anonymised during review.

\section{Copyright:}

(c) 2020, Lara Furniss. This is an open-access article distributed under the terms of the Creative Commons Attribution Licence (CC BY) 4.0 https://creativecommons.org/licenses/by/4.0/, which permits unrestricted use, distribution and reproduction in any medium, provided the original author and source are credited $\bullet$ DOI: https://doi.org/10.14324/111.444.amps.2020v18i1.004.

\section{Open access:}

Architecture_MPS is a peer-reviewed open-access journal.

\begin{abstract}
Since 2000, design practice in the UK has changed dramatically. Boundaries between design disciplines have dissolved, and many contemporary design studios now defy classification. These studios are reconfiguring the design landscape, yet a uni-disciplinary structure still dominates undergraduate education. This is creating a disconnection between practice and education and posing critical questions for the current design education system. This article outlines the findings of a $\mathrm{PhD}$ research study exploring this disconnection, and although situated within the UK, the findings have international relevance. An initial scoping exercise draws on interviews with leading commentators from the UK design sector, examining the evolution of design practice over the past 10 years, and possible future directions for undergraduate education. Findings highlight that UK policy for creative education has placed undergraduate design courses in potential crisis. Arguably, the current university system for design education is outdated. It is now necessary to redefine the skills and processes twenty-first-century designers need. The body of the research is situated within five internationally renowned creative studios
\end{abstract}


which defy classification. In-depth ethnographic studies cross-analyse the creative processes of these studios and their views on education. Findings identify key components of each studio's processes, while also exploring studio members' educational experiences, and reflections on future implications for pedagogy. This article argues that this growing disconnect between practice and education calls for existing pedagogic models to be challenged, proposes alternative approaches and highlights the need for policymakers, practitioners and educators to work together to best prepare young designers to meet today's challenges.

Keywords: design pedagogy; education policy; design practice; design professionals; organizational structures; case studies; collaboration 


\section{Introduction}

Design practice in the UK has changed dramatically in the past two decades. Boundaries between design disciplines have dissolved, and many contemporary design studios now defy classification. This article explores these ongoing shifts in design practice and the implications of these for contemporary design pedagogy. First, a review of extant literature explores evolutions in design practice, perceived disconnections with design pedagogy and the role and evolution of policy. A scoping exercise then draws on interviews with expert and leading commentators from the UK design sector. Next, the summaries of five case studies are presented: the cases concern five internationally renowned creative studios, each of which is characterized by an approach that defies current classifications. These summaries then provide a basis for comparative case analysis and interpretation. Finally, the article concludes with recommendations for undergraduate education, proposing alternative approaches to teaching and learning that better meet with progressive, and successful, trends in design.

\section{Practice}

Interdisciplinary practice is nothing new, and the specialist versus polymath debate has been ongoing for centuries. ${ }^{1}$ The 'design generalist is mostly met with scepticism', ${ }^{2}$ yet throughout the twentieth century, hybrid, universal individuals took a comprehensive view, re-defining design and preparing the ground for the twenty-first century. Now, 100 years since the formation of the Bauhaus, it would appear we are again at a similar moment, with the rise of the 'polymath interloper'. ${ }^{3}$ The specialist has not gone away, but many practitioners now defy traditional classification in favour of moving fluidly across the fields of art, design and architecture. ${ }^{4}$ We are arguably witnessing a significant paradigm shift, ${ }^{5}$ with practitioners 're-defining what design is', ${ }^{6}$ and moving from designing products to designing for 'people's purposes' ${ }^{7}$ Key methods include: collaboration; co-designing; and 'seeing, thinking, and doing differently'. ${ }^{8}$ Terminology and classification systems for design are becoming more complex, and it appears that simplicity is needed to de-mystify design and avoid a 'terminological quagmire'. 9

\section{Pedagogy}

Perhaps surprisingly, few studies have explored this disconnection between evolving polymathic practice and specialization in higher education. Key texts, including Rawsthorn, ${ }^{10}$ Williams ${ }^{11}$ and Coles, ${ }^{12}$ capture evidence and examples of the evolution of professional practice, but do not address implications for pedagogy. Arguably, in light of the practical evolution, 'the impact upon the education of designers will be immense' ${ }^{13}$ Today, UK higher education creative arts and design courses are regarded as successful in terms of recruitment, ${ }^{14}$ with the highest number of design students in Europe. Yet, courses follow a uni-disciplinary structure, especially at undergraduate level, ${ }^{15}$ and are resistant to interdisciplinarity due to rigid systems and an industrial model of education. ${ }^{16}$ The twentieth century witnessed an explosion of radical, interdisciplinary pedagogical models, including the Bauhaus ${ }^{17}$ and the New Bauhaus, ${ }^{18}$ that reacted against the industrial model and responded to rapid developments in technology. These institutions shared a quest for a universal design pedagogy, and despite much political resistance, challenged the system. This century now requires 'a fundamental change in education' ${ }^{19}$ and a new kind of university.

\section{Policy}

The UK design sector is the second-largest in the world, and the largest in Europe. ${ }^{20}$ However, there are no identifiable design policies or action plans in the UK. ${ }^{21}$ Education policy appears to be devaluing creativity at all levels, ${ }^{22}$ demonstrated by a clear decline in arts subject entries at GCSE (General Certificate of Secondary Education) as a result of 'the triple pressure of the EBacc, Progress 8 and wider financial issues within schools' ${ }^{23}$ There is a need to turn STEM (science, technology, engineering, maths) into STEAM, adding arts subjects, as a narrow focus on science, technology and maths will not deliver the innovation and creative thinking needed. ${ }^{24}$ The UK 'cannot be complacent ${ }^{\prime 25}$ about the current economic success of the creative industries and must commit to designing the education and skills frameworks to support this sector, where jobs of the future will be found. Policy makers in the UK could take inspiration 
from Finland, ${ }^{26}$ which used a 'joined-up' policy mode ${ }^{27}$ to remove teaching by subject at the secondary level, in favour of teaching 'topics'. ${ }^{28}$

\section{Scoping Exercise}

To gain a broader understanding of evolving practices in the UK, a scoping exercise was first undertaken that drew on interviews with 12 leading commentators from the UK design sector. Published in 2015, these findings ${ }^{29}$ highlighted that the practice of design in the UK is now unrecognizable from what it was 10 years previously, due to role redefinition, process reinvention and continual evolution. Also, UK policy for creative education has placed undergraduate design courses in potential crisis and the current university system is outdated. It is now necessary to redefine the skills and processes that contemporary designers need. Key recommendations included examining current practice to better understand the processes and skills young designers will need to meet the challenges of coming decades.

\section{A Study of Five Design Studios: Practice and Pedagogy}

In response to these recommendations, the main body of the study was situated within five internationally renowned design studios which defy classification. The aim was to examine similarities and differences between studios in terms of practice and pedagogy. An in-depth ethnographic method was used to interview ${ }^{30}$ and observe a cross-section of members. ${ }^{31}$ Data was cross-analysed ${ }^{32}$ to facilitate comparisons and produce comparative case studies. ${ }^{33}$ Selection criteria was based on all studios needing to: cross art, design and architecture; ${ }^{34}$ be based in the UK; and have an international reputation. Differences included variety in work produced, year established and size. The studios include Ron Arad Associates, Heatherwick Studio, Jason Bruges Studio, Punchdrunk, and Assemble (recent Turner Prize winners). The study was conducted between 2015 and 2016, and selected findings are presented below.

\section{Ron Arad Associates}

At the time of the study, the Ron Arad Associates studio had been established for approximately 40 years and comprised 20 members. Six were interviewed to capture a cross-section of roles. The studio is located in Chalk Farm, London, within a former piano workshop and clothing factory. With an education background in fine art and architecture, Arad made his name designing chairs and describes what he does as 'no discipline'. ${ }^{35}$ Work ranges from eyewear and interiors to installations and buildings. The philosophy is to break convention, do something new and be innovative.

Arad's pluralist, non-conformist educational experience has clearly defined both his practice and pedagogic approach, which in turn has left a lasting legacy on both creative practice and education. The work of the studio has shaped the current creative landscape by inspiring leading designer-makers to take design from a reactive to a proactive self-motivated process, often setting their own briefs to create self-generated work. This was driven by Arad starting out not knowing how to define what he did, refusing to be labelled, breaking conventions and approaching everything with a pluralist outlook.

Despite crossing art, design and architecture, the studio's work is mostly three-dimensional and is unified by human interaction and innovation. Key components that drive the process include: back-and-forth ideas exchange like playing a game of table tennis; asking 'what if?'; demanding time and quality; making and materiality; and pioneering new technologies. Figure 1 is an interpretive diagram of the iterative, back-and-forth process between Arad and a studio member leading a project. Making and materiality are at the core of all projects, whether creating in-house or with trusted external partners. All work is object-based with an artisanal approach. Although an atelier model, the hierarchical structure is relatively flat, with constant collaboration. The small size means roles are broad and fluid, with an emphasis on skillsets and personality over disciplinary labels. The studio members interviewed have diverse backgrounds that do not follow prescriptive routes, and key attributes include confidence, curiosity, tenacity and initiative. Refusing to expand its size has preserved a studio culture, where decisions are made by consensus, everyone has a voice, and members show commitment to Arad. The studio space is used to declare a bohemian agenda; challenge the preconceived notions of what an office should be; 
and provide a playground for creativity, experimentation and fun. The workshop is a vital laboratory for exploration and a visual reminder that making is still a fundamental part of the philosophy.

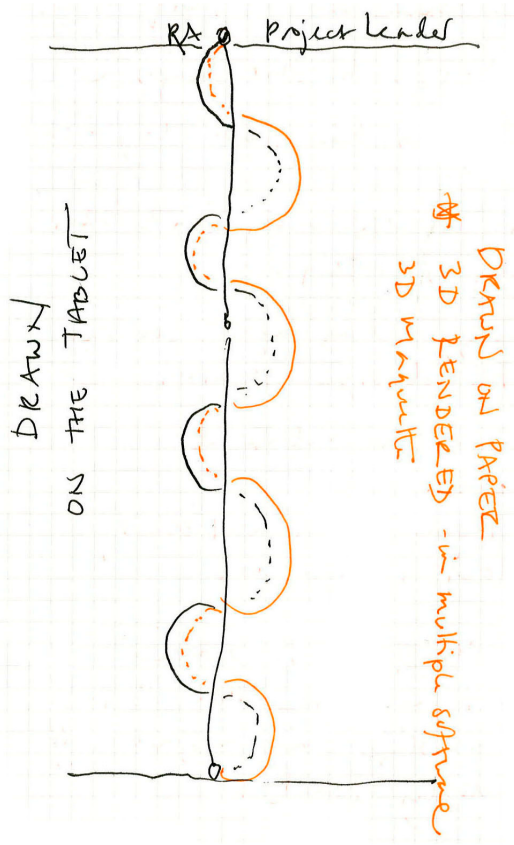

Figure 1 Interpretive process diagram for Ron Arad Associates (Source: Author, 2020).

Arad's rebellious approach to teaching has had a major impact on creative education as he teaches with no agenda and prioritizes guided exploration over professional preparation. In the mid-1990s at Vienna's Hochschule für angewandte Kunst, Arad created a general design undergraduate course. Then, in 1998, along with Daniel Charny and Hilary French, Arad led a change in design education by creating the Design Products course at the Royal College of Art, with the belief that defining courses by disciplines was no longer relevant.

Studio members are drawn from non-conventional, fluid, pluralist educational backgrounds where they enjoyed unfettered freedom. The studio believes that education should provide freedom, embrace failure, prepare students to think beyond the limitations of one discipline, look to European courses, remove disciplinary divisions, emphasize transferable skills and encourage self-criticism and risk taking. Interviewees propose re-defining design to better understand the fundamental skills a designer needs and the reality of the way designers work, and they wish to see the government better support secondary education.

\section{Heatherwick Studio}

At the time of the study, Heatherwick Studio had been established for approximately 25 years and comprised 178 employees. Eight were interviewed to capture a cross-section of roles. Situated in the heart of Kings Cross, London, the studio comprises five buildings, all within five minutes' walk of each other. With an educational background in three-dimensional design, Heatherwick considers all design not as multidisciplinary, but as a single discipline: three-dimensional design. ${ }^{36}$ Projects range from Christmas cards made of resin and the 2012 Olympic cauldron to rolling bridges and power stations. The philosophy of the studio has clearly been inspired by Victorian entrepreneurs and master builders.

Through a three-dimensional design lens, the studio looks for new typologies to produce exceptional projects. Whether a building, piece of furniture or Christmas card, projects emerge through rigorous questioning and extreme iteration. Figure 2 is an interpretive diagram of the process, which is emergent, iterative and requires continual questioning, making, zooming in and out from the micro-scale to the macro-scale and eliminating. Making and materiality are key at every stage, as is practical analysis. 
Continually zooming in and out enables the studio to work at human scale. Through brutal critiquing, self-reflection and collaborative discussion, members redefine what they believe 'good enough' is. Despite clear hierarchical structure at the top of the organization, at project level the structure appears relatively flat. Teams are varied in ability and skills, and a considered approach is taken to hiring staff who demonstrate lateral thinking and an open-minded attitude towards disciplines. Core capabilities include self-criticism, self-confidence, strong verbal and visual communication, a universal outlook, curiosity, determination and a sense of humour.

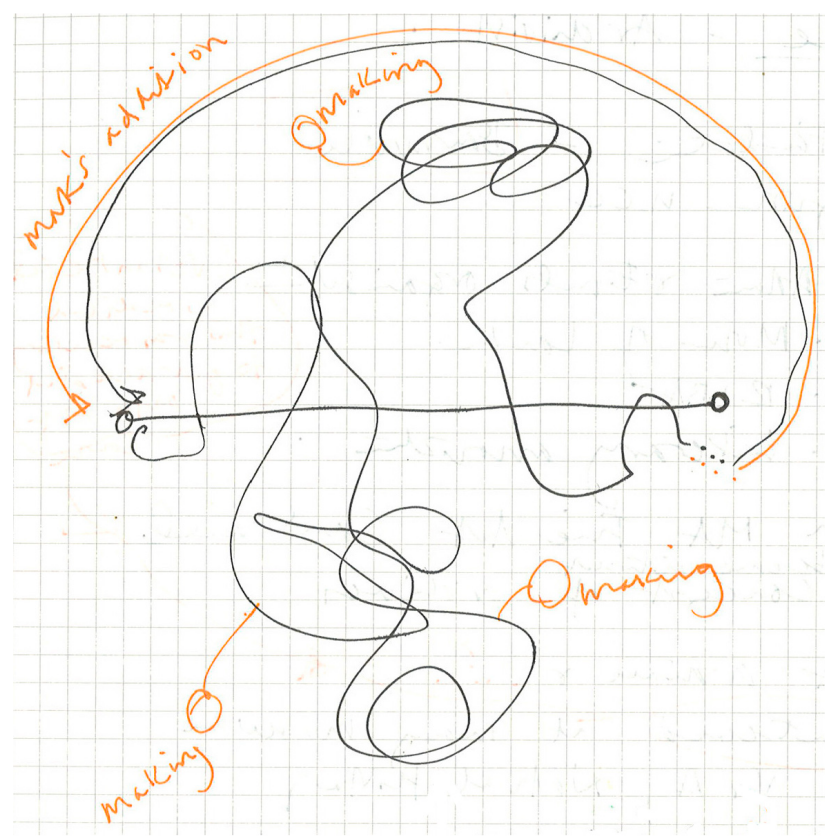

Figure 2 Interpretive process diagram for Heatherwick Studio (Source: Author, 2020).

The design of the studio is very considered, with objects from diverse disciplines used to stimulate interest, innovation, excitement of form, materiality and colour. A flexible, open-plan layout is a statement of transparency, supports a holistic one-world view, and encourages communication and cross-fertilization. Placing the workshop at the centre of the studio sends a clear message of intent, symbolizing the beating heart of the studio. Making the strategic decision to hire senior advisors with extensive knowledge of design, procurement, policy and infrastructure has supported the move from smaller-scale projects to now primarily working on strategic projects, designing buildings and thinking about cities. As a result, the studio has expanded from one site to five, with a dramatic rise in studio members. The main challenge for the studio appears to be the management of growth while maintaining the cultural qualities.

The studio members interviewed come from diverse educational experiences that encouraged freedom, breadth and agility. The studio's recent involvement in secondary education was a collaboration with the Victoria and Albert Museum (V\&A) Schools' DesignLab and the art department at Whitecross High School in Hereford, UK. Pupils toured the collections of the V\&A, to give them a better understanding of different materials, and were then given briefs to analyse, pairing a challenge with a collection. For example, one challenge was to create a seat that can only function when two people occupy it, and the collection was glass. This challenged students to redefine their understanding of the word 'design' and enabled them to see, due to the cross-disciplinary nature of the studio, that things do not exist in isolation.

The studio believes undergraduate education should look for a broader, simpler definition of design and disciplinary classifications and provide suitable studio space for cross-disciplinary work. Instructors should encourage depth of thinking through rigorous questioning and emphasize process and failure over the end product. Concerns include a disconnection between education and practice and a fundamental lack of understanding of the industry within education. The studio highlights that non-design trained designers 
are also challenging the notion of a comprehensive design education. This shared holistic understanding of the work, defining every project under the universal banner of three-dimensional design, creates a clarity and simplicity that could have significant impact not only on the sector, but also on education and policy in terms of classification, categorization and implementation.

\section{Jason Bruges Studio}

At the time of the study, the Jason Bruges Studio had been established for approximately 15 years and comprised 20 members, of whom five were interviewed. Situated in London, between Old Street and Shoreditch, the studio is located within a gated mews. With an educational background in interactive architecture, the original aim of the studio was to investigate architecture that could perform, change and interact. The work sits in the intersection between installation art, time-based four-dimensional architecture and interaction design and cybernetics. Projects include: interactive doors and hospital corridors; performative installations; and responsive, illuminated architectural façades. The philosophy is to innovate, improve the environment and make people's lives better.

Setting out to investigate architecture that could perform, change and interact, the work emphasizes curiosity and innovation, is human-centred and focuses on connecting to the environment. The process is the same for a stand-alone artwork in a gallery, an intervention in a public space or a collaboration with an architect. Ideas are emergently grown and then fluidly percolated through a series of iterative loops, reviewing and refining. Figure 3 is an interpretive diagram of the process which requires percolation by reviewing and refining; prototyping, testing and making; pushing boundaries; and human interaction.

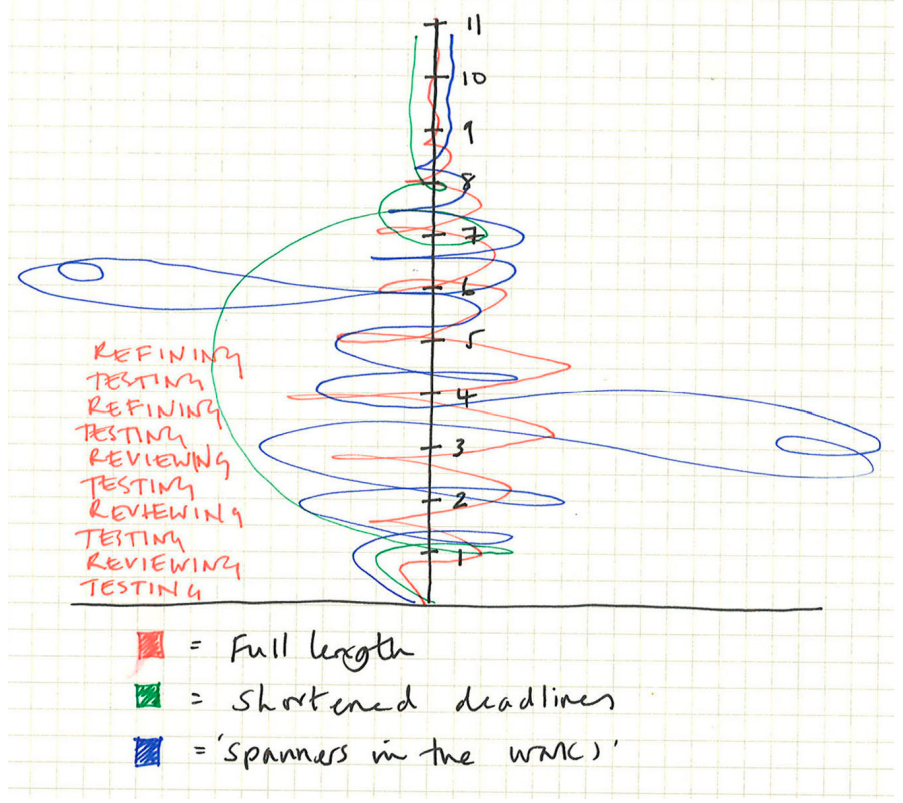

Figure 3 Interpretive process diagram for Jason Bruges Studio (Source: Author, 2020).

As designer-makers, continual prototyping and re-testing in house enables agility. Animated visualization is crucial to communicate how designs will perform and react. Taking risks, breaking rules and pioneering new technologies are all encouraged. Apart from a basic hierarchy, the structure is otherwise unconventionally flat and fluid. Teams are selected based on availability and skills, and Bruges regards members as 'the sum of all parts, like an orchestra'. The studio thrives on the diversity of its members, who wear multiple hats. Members enjoy learning new things, are inspired by each other and arguably do not want to be limited by their own disciplines. Core capabilities include an interest in hybrid worlds, holding a wide range of skills and interests, originality and self-motivation and a lack of ego. The studio is eclectic in feel with the workshop at its heart. The workshop (used for electronics, wood 
and model making) plays a vital role in enabling agility and iteration, encouraging play and providing an infectious environment where members creatively inspire and motivate each other.

Studio members come from hybrid, non-traditional educational experiences that encouraged disruption, lateral thinking, a sense of freedom and the confidence to jump sideways. Bruges believes it is crucial for UK education to stay nimble; to emphasize process and thinking; and to collaborate and partner with industry. Bruges teaches at the Bartlett, as well as other institutions, including the Royal College of Art. He recommends that private enterprise must support the university system to ensure graduates are fit for purpose for the jobs available and sees it as an ecosystem that benefits everyone involved. The studio believes education should deprogram first-year students of preconceived assumptions, encourage curiosity, provide cross-disciplinary working, and encourage self-definition rather than accepting traditional labels. Other suggestions include providing constant collaboration, bringing in tutors from different disciplines to demonstrate transferable skills, and making failure an assessable outcome.

\section{Punchdrunk}

At the time of the study, Punchdrunk had been established for approximately 10 years and comprised 27 permanent employees (with a volunteer network of 400), of whom five were interviewed. There are three fixed locations: The Store in Newham, East London, where props are kept and sets built; an office in Shoreditch; and a private members' club, Shoreditch House. The employees have educational backgrounds in theatre; their mission is to make audiences feel punch-drunk by exploring new ways of storytelling and engaging with audiences. ${ }^{37}$ The work is site-sympathetic and experiential, and about personal exploration, non-linear storytelling and creating epic worlds. Projects range from one-to-one performances in a cupboard to experiences in museums, care homes, warehouses and across cities.

Through constant reinvention, pushing boundaries and high risk taking, the studio has pioneered a new genre of live performance, challenging audiences to engage in experiences that are more real, physical and visceral. Placing audience and site at the heart of the process, each show grows through extreme iteration, 'method designing' (a term coined by the author reflective of method acting), innovative use of technology and a deep level of attention to detail. Endless development means that shows constantly evolve. Figure 4 is an interpretive diagram of the process which always starts with the site and grows through world creation, with an audience focus that continues throughout the life of a project.

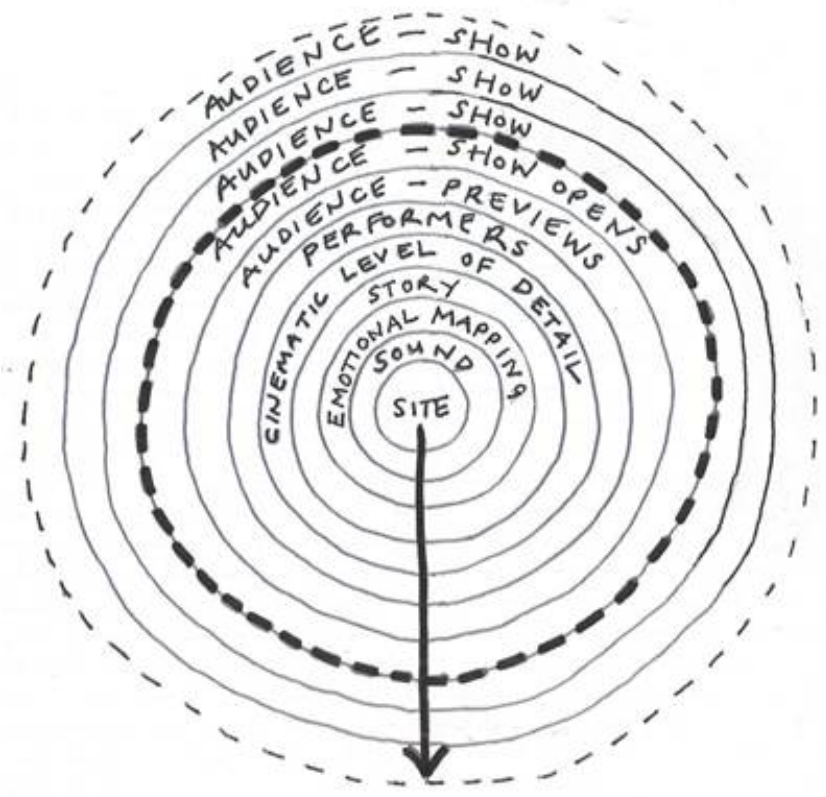

Figure 4 Interpretive process diagram for Punchdrunk (Source: Author, 2020). 
With strong artistic vision at the top, the studio works holistically as an ensemble, with shared language and a symbiotic way of creating. Mass collaboration occurs at times between the studio and a wider net of volunteers. Roles are multifaceted, requiring members to have broad skillsets. Key personal attributes include an audience focus, commitment to quality and being a team player. Collaboration with brands and wider evolution of the genre have enabled the studio to develop more ambitious work, and they see themselves currently in the third act of a five-act play. Being split over three locations, and the need to be itinerant, has created obvious conflicts. A planned move to a new site will bring everyone under one roof and should solve this issue. Addressing the need for growth while creating an environment that allows the studio to work in the experimental way it did when first formed is ground-breaking for the sector and will undoubtedly play a key role in future studies on studio practice and evolution.

By taking processes successfully used in large-scale commercial shows and applying them to educational and social projects, Punchdrunk has also established Punchdrunk Enrichment which sets an excellent example for the rest of the sector. One Punchdrunk Enrichment project is The Lost Lending Library that has been running since 2014 across many primary schools in London and is based on the premise that a library mysteriously lands within the walls of a school and needs pupils to feed it with new stories. The impact on primary education alone has been profound. As with the larger shows, Punchdrunk Enrichment focuses on placing audiences in a liminal state, encouraging curiosity and developing a sense of agency, all cited as vital ingredients in progressive creative educational models by leading experts, including Sir Ken Robinson. ${ }^{38}$ The work is inclusive, demonstrating how all of society can benefit from creativity and storytelling. Studio members come from broad, agile educational experiences, where making, the importance of failure and use of space were prioritized. The studio believes education should encourage experimentation, remove reductive disciplinary labels, support cross-departmental work and break down the notion of succeeding in favour of valuing failure. They also believe the government, universities and industry need to invest more in creative education and rethink tuition fees to create a culture which continues to produce artists, makers and creators.

\section{Assemble}

At the time of the study, the Assemble studio had been established for approximately five years and comprised 13 members of whom eight were interviewed. The studio is located in Stratford, East London, within the ruins of Victorian industrial buildings, soon to be demolished. The studio, whose members have educational backgrounds in architecture, was formed out of collective frustration with the traditional architectural studio model and a desire to make. Members define themselves as a collective working across art, design and architecture and the work is socially rooted and human-centred. Projects range from playgrounds, pop-up theatres and art galleries, to community workshops and strategic interventions in city streets and parks.

Working across design, art and architecture, the studio prefers to avoid labels that might be misinterpreted. Co-created with communities, and dependent on the people using them to make them a success, the projects evolve over time and are often of an ephemeral nature. The studio focuses on diverse projects that support urban creative workspaces and social spaces, both currently under threat from real-estate markets.

Figure 5 is an interpretive diagram of the process, which requires collective decision making, co-creative collaboration, self-initiating briefs, creative management and making by hand. Through constant conversation, not only with fellow members but also the wider creative community, the studio thrives on questioning. Making is fundamental to the philosophy and is part of every project, whether testing, prototyping or realizing. Members of the public are treated as collaborators, rather than clients, and are encouraged to shape and build their environments and to continue to evolve projects. Briefs are usually self-initiated, growing out of social and community needs, or heavily shaped through a holistic process. Creative management is key to the success of all projects, thinking beyond the initial design to look at how to sustain projects and build legacies. Hierarchy is flat, with all members assigned a director role. Teams of two members propose and run projects with wider support provided at weekly design reviews. Personal commitment to each project is critical. There are no divisions between disciplines, and diverse skills and 
backgrounds are embraced. Core capabilities include a can-do attitude, a collective mentality, having fun and prioritizing socializing. The studio space is crucial to enable flexibility and agility to make at any scale and to encourage conversations with craftspeople from other disciplines.

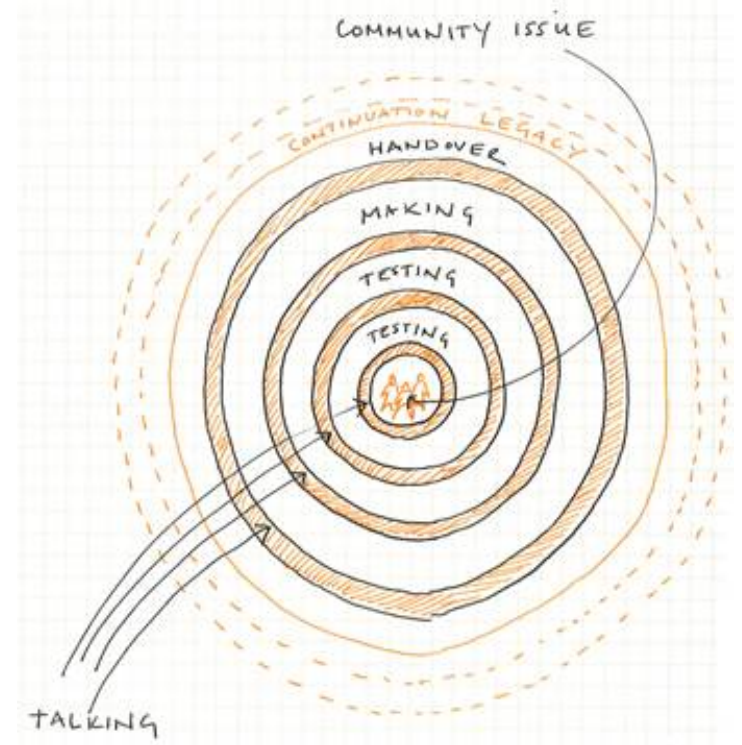

Figure 5 Interpretive process diagram for Assemble (Source: Author, 2020).

Assemble is evolving organically to preserve its open, collective culture. With no desire to grow significantly larger, members are aware that more growth may be necessary as projects increase in size and number. Winning the Turner Prize raised many questions and resulted in a formal summit. This produced a plan which looked ahead to the next five years and included a vision for a far larger co-operative creative workspace that could support public activities, events and teaching.

Most Assemble members hail from a cohort of a small architecture undergraduate degree courses that focused on the public and making. As freelancers, many teach in formal education, and two members have recently taken up interdisciplinary posts as 'virtuoso professors' at Liverpool John Moores University, where they offer open tutorials with any student from any course. The studio also explores alternative educational models, embedding teaching into the creative workshop facility spaces they have established. Members believe education should provide space for students to occupy, provide sufficient time to experiment, support failure, enable fluidity and breadth, encourage constant collaboration and make a foundation course compulsory.

\section{Analysis and Interpretation}

\section{Origins}

All five studios studied formed out of the same desires to explore new ways of working and innovating. All saw designing and making as key to this process. Studio members had to invent their professions, processes and business models. By breaking with conventions, they were able to innovate and create new types of work and new ways of working. Courage is a central character trait found in those who stepped outside of traditional models.

\section{How They Define Themselves and Their Work}

Asking interviewees to define themselves is a difficult question. Interviewees physically communicate this challenge by taking a deep breath, pausing, sighing, slumping their shoulders or laughing. Some give simple, one-word answers, while others fall back on apparently well-rehearsed complex descriptions. Most of the responses describe the work itself rather than the worker. Traditional disciplinary labels do not support how these studio members communicate with, or are understood by, the outside world. 
For Assemble, architecture is 'more about people sitting around a table than the space they're inhabiting'. ${ }^{39}$ Two common terms used to describe the work are identified as scale (varying from small to large) and dimension (three-dimensional or four-dimensional). They are 'moving beyond discipline', ${ }^{40}$ and approach designing with this 'attitude' ${ }^{41}$ Interviewees reflect Foucault's description of 'universal individuals ${ }^{42}$ who do not sit in a particular disciplinary location, as well as Krznaric's interpretation of the 'wide achiever' ${ }^{43}$ who values a breadth of interests over high achieving in one area of interest.

\section{Organizational Structures}

All five studios are structured to reflect their individual innovative business models. However, three commonalities include relatively flat hierarchies, fluid collaborative team structures and individuals with multifaceted roles. All studios use flat, or relatively flat hierarchical structures, highlighted by interviewees as rare in the wider world. Team structures appear fluid, continually evolving and highly collaborative. Ron Arad Associates and Assemble work in pairs, with other members playing support roles where needed. Heatherwick Studio, Jason Bruges Studio and Punchdrunk use larger, multifaceted teams from a broad range of disciplinary interests. External collaborators are critical in varying ways for all studios, whether collaborating with co-creators, volunteers or expert specialists. Individual members have multifaceted roles which require interdisciplinary thinking, being well-rounded, open-minded and open to broad conversations.

\section{Design Process}

The processes for all five studios are rooted in emergence, iteration and being human-centred. The core commonality is that each studio uses emergent logic to create a process that is non-linear and unique for every project. Work is grown and continues to grow, endlessly developing and evolving. Any formal process structure is treated only as a guide. Iteration is essential to enable this process of emergence, described as 'extreme, messy and exhausting', which are terms not commonly heard when designers discuss the creative process, yet these provide a true picture of the challenges the designers face. Projects are human-centred and highly collaborative. Key components common to the processes of all studios are:

Making: Prototyping, testing, making, being designer-makers

Questioning: Rigorous questioning, pushing boundaries

Eliminating: Celebrating failure, taking risks

Innovating: Embracing innovation and new technologies

Communicating: Including both verbal and visual communication

To capture this common process model more accurately, the interpretive process diagrams created for each studio were cross-analysed, and the results amalgamated into a new emergent process model. As each project grows upwards, ideas are gradually refined through messy, iterative loops. At the core of the model is the work itself, and the nucleus within this core consists of the people who live and drive emergence. This emergent process model is viewed in overhead plan view (Figure 6).

\section{Spatial Requirements}

The studios could not apply these innovative processes without the physical spaces they have created for themselves, spaces carefully considered. Making is placed at the heart, and layouts are open plan, flexible and adaptable. The look of each studio is a physical representation of its creator's philosophy. Placing the workshop at the centre of each studio creates a laboratory environment, and a place of doing, enabling agility and iteration and encouraging play. Having an informal type of space where they can make noise, test and build, and leave a mess is critical. Being open plan in layout is essential as it provides a level of efficiency, is a statement of transparency and is seen as key to collaboration and communication. 


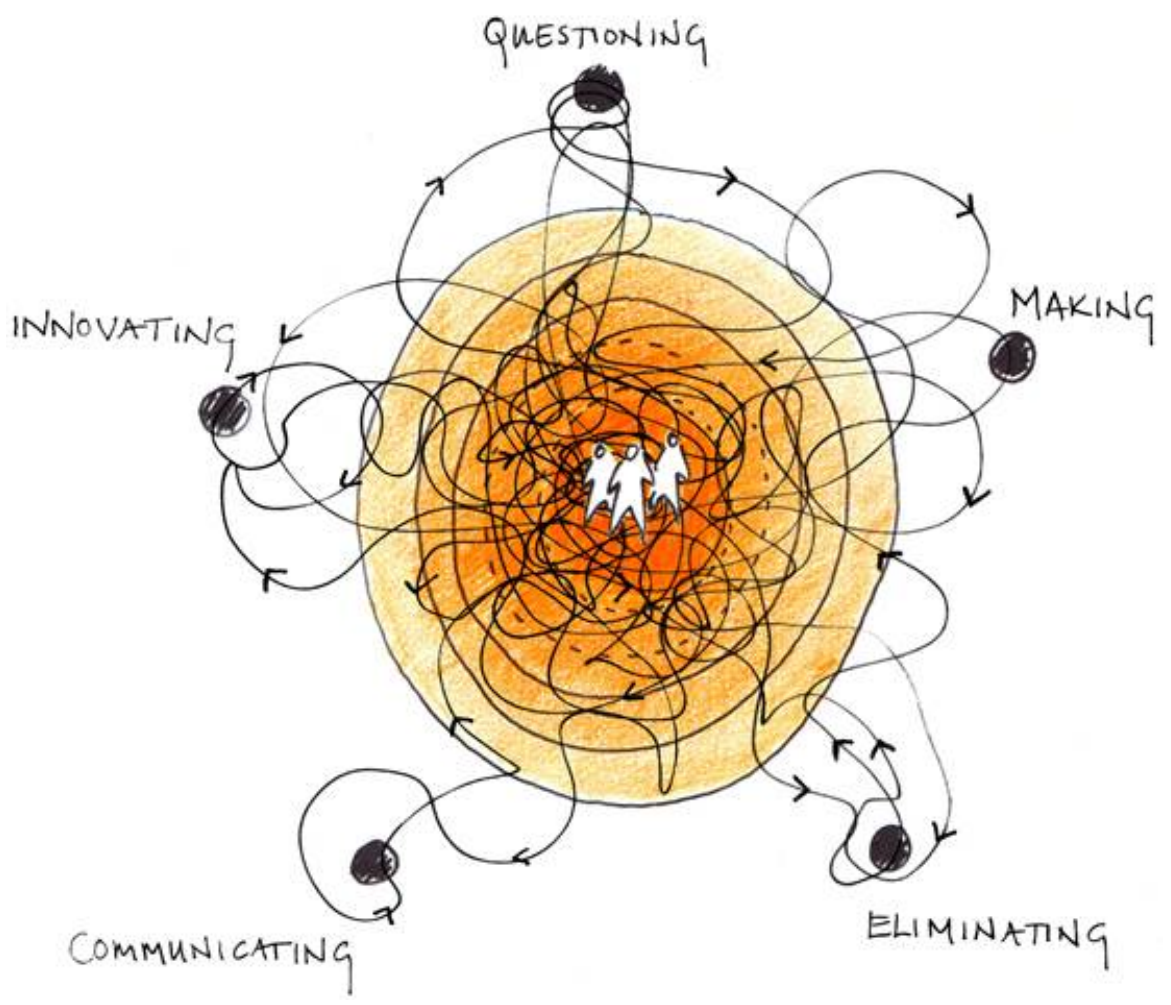

Figure 6 Emergent process model - plan view (Source: Author, 2020).

\section{Core Capabilities}

Key to the success of each studio is the careful selection of exceptional members who have both the technical and social skills to creatively collaborate. Being able to collaborate and fit into the studio environment are regarded as essential, and social skills are placed top of the list. This is evident in the fact that every studio has members who are not formally trained in design. Due to the diverse nature of their work, the studios select members who are universal in their outlook and have a hybrid broad skills base. Self-confidence and an attitude to both criticize and drive yourself forward are highlighted as necessary for the agility to step outside the confines of traditional disciplines. Curiosity and tenacity are highlighted as important to avoid stagnation. A commitment to quality and attention to detail are essential, and core communication tools include sketching, model making, three-dimensional modelling and verbal communication, whether presenting a project or developing narratives.

\section{Recommendations for Undergraduate Education}

There is a symbiotic relationship between pedagogy and practice for these studios. Interviewees' previous educational experiences have informed their practice. In turn, their practice now informs their involvement in education. The key commonality between interviewees is that they either selected non-conventional courses of study or were allowed to break the rules at their more conventional institutions.

The studios believe that undergraduate education needs to prepare students to think beyond the limitations of a single discipline, to open their horizons to the shared definitions of design and to capture the true messiness of reality. Interviewees propose that giving students time to experiment and fail, and encouraging risk taking, are essential and something that higher education does not currently support. They identify that current disciplinary courses need to be redefined and propose that students should be encouraged to define themselves rather than letting others pigeonhole them. Suggestions include looking at commonalities between disciplines that are currently not allowed to be common. For example, three-dimensional design could include automotive products, building design, engineering and construction. Two-dimensional design could include photography, graphics and painting. Another suggestion is taking inspiration from the foundation diploma course and building it into a degree-level 
course to enable undergraduate students to continue exploring with options for specialization later. Having a physical space in which students can make a mess and collaborate is highlighted as essential and something that is currently diminishing in undergraduate education. Finally, interviewees recommend enabling students to collaborate, as well as building collaboration between higher education and practice, to create a strong ecosystem.

To capture these recommendations, the new emergent process model can also be viewed as a potential pedagogical model. Taking an integrative approach that combines the dimensions and scale configuration, with the notion of emergent process, provides the foundation for a novel emergent pedagogy. This model could offer higher education students the opportunity to work across all dimensions and scale in the early stages of a degree, with options to gradually narrow down, should they wish, through undergraduate and into master's level. Figure 7 shows this possible emergent pedagogical model. Students move through all two- (yellow), three- (red) and four-dimensional (blue) areas in the first year of study, to then gradually narrow down as they choose. For example, a student who wishes to focus on commercial fashion could explore two, three and four dimensions in the first year for initial richness of breadth, then narrow down to small-scale three-dimensional work with discipline-specific skills in the third year. In contrast, a student who wishes to explore fashion in a broader sense, merging the disciplines of fashion, engineering, interaction design and experience design, could continue exploring the breadth of three and four dimensions throughout their studies, without limitations. Treated as a recipe for pedagogy, these findings and recommendations could offer innovative solutions to support higher education.

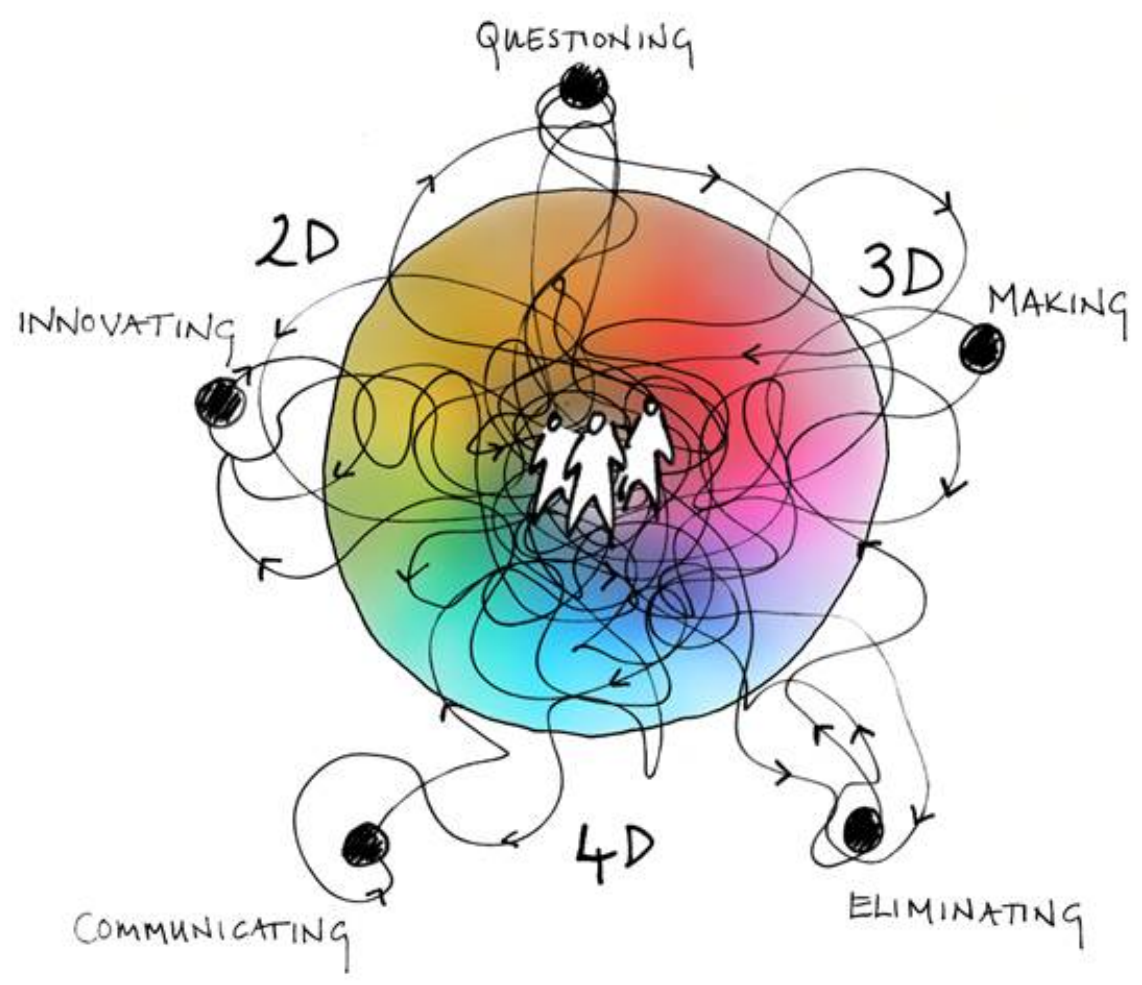

Figure 7 Emergent pedagogical model - plan view (Source: Author, 2020).

\section{Conclusion}

Much can be learned from the pioneering practices of these studios. Treated as a recipe for practice, the common approaches to organizational structure, use of space and core capabilities could be applied to help innovate any design studio. The emergent process model could be applied to enable studios to build creativity and develop breadth of work. This recipe could also be applied to businesses generally 
who want to innovate, and higher education could interpret the recipe to become more agile, relevant and connected to evolving practice.

The findings show a much simpler approach to terminology and classification than expected. The outside world appears to over-complicate what is inherently simple within the studios, which for the studios is best described using scale and dimensions. This approach could be applied to all levels of education, starting at primary and secondary, as a much simpler way to introduce art, design, craft and technology to encourage students 'to extend themselves beyond specialized points of view' ${ }^{44}$ It could be argued that design has moved beyond discipline ${ }^{45}$ to purpose and that designers employ dimensions and scale to frame ${ }^{46}$ each project with a universal attitude. ${ }^{47}$

This study raises concerns for the current state of undergraduate design education. Treating the recommendations as a recipe for pedagogy could enable the creation of a more relevant curriculum and a common language for design, which in turn could enable the sharing of methodology. Valuing the symbiotic relationship between practice and pedagogy is critical to creating an integrated curriculum, and practitioners, educators and policy makers need to come together to prevent what appears to be the devaluing of creativity at all levels of education. A STEAM education must be offered to ensure high-quality cultural and creative education at all levels and to position the UK as a key player in the Fourth Industrial Revolution. ${ }^{48}$

\section{Declarations and Conflict of Interests}

The author declares no conflict of interests with this work.

\section{Notes}

${ }^{1}$ Root-Bernstein, 'Multiple Giftedness in Adults'.

${ }^{2}$ Eckert, 'The Y-Shaped Designer', 137.

${ }^{3}$ Seymour, 'Recruitment: Heads or Tails'.

${ }^{4}$ Coles, The Transdisciplinary Studio.

${ }^{5}$ Coles, The Transdisciplinary Studio, 322.

${ }^{6}$ Williams, 21 Twenty-One, 7.

${ }^{7}$ Sanders and Stappers, 'Co-creation and the New Landscapes of Design', 10.

${ }^{8}$ Dorst, Frame Innovation, 133.

${ }^{9}$ Choi and Pak, 'Multidisciplinarity, Interdisciplinarity', 352.

${ }^{10}$ Rawsthorn, Hello World.

${ }^{11}$ Williams, 21 Twenty-One.

${ }^{12}$ Coles, The Transdisciplinary Studio.

${ }^{13}$ Sanders and Stappers, 'Co-creation and the New Landscapes of Design', 11.

${ }^{14}$ HESA, 'Higher Education Student Statistics'.

${ }^{15}$ Max-Neef, 'Foundations of Transdisciplinarity', 5.

${ }^{16}$ Robinson and Aronica, Creative Schools.

${ }^{17}$ Lerner, 'Foundations for Design Education'.

${ }^{18}$ Findeli, 'Rethinking Design Education'.

${ }^{19}$ Friedman, 'Models of Design', 150.

${ }^{20}$ Creative Industries Council, 'The UK Design Industry'.

${ }^{21}$ Whicher, 'Reflections on Design Action Plans'.

${ }^{22}$ Creative Industries Federation, 'Creative Education Agenda'.

${ }^{23}$ Johnes, 'Education Policy Institute'.

${ }^{24}$ Creative Industries Federation, 'Creative Education Agenda'.

${ }^{25}$ Bazalgette, 'Independent Review of the Creative Industries'.

${ }^{26}$ Ministry of Education and Culture Finland, 'Design Finland Programme'.

${ }^{27}$ Korvenmaa, 'Finland, Design and National Policies of Innovation'.

${ }^{28}$ Garner, 'Finland Schools'.

${ }^{29}$ Furniss, 'Beyond Discipline'. 
${ }^{30}$ Kvale and Brinkmann, InterViews.

${ }^{31}$ Emerson, Fretz and Shaw, Writing Ethnographic Fieldnotes.

${ }^{32}$ Marshall and Rossmann, Designing Qualitative Research.

${ }^{33}$ Denscombe, The Good Research Guide.

${ }^{34}$ Coles, The Transdisciplinary Studio.

${ }^{35}$ Arad and Antonelli, Ron Arad, 9.

${ }^{36}$ Heatherwick, Making.

${ }^{37}$ Ivanauskas, 'Interview with Felix Barrett'.

${ }^{38}$ Robinson, The Element.

${ }^{39}$ Dawood, 'Assemble'.

${ }^{40}$ Nicolescu, 'Transdisciplinarity'.

${ }^{41}$ Moholy-Nagy, Vision in Motion, 42.

${ }^{42}$ Chettiparamb, 'Interdisciplinarity'.

${ }^{43}$ Krznaric, How to Find Fulfilling Work, 17.

${ }^{44}$ Friedman, Mendini, Deitch and Holt, Dan Friedman, 40.

45 Nicolescu, 'Transdisciplinarity', 142.

${ }^{46}$ Dorst, Frame Innovation.

${ }^{47}$ Moholy-Nagy, Vision in Motion, 42.

${ }^{48}$ Gray, 'The ten skills you need to thrive in the Fourth Industrial Revolution'.

\section{References}

Arad, Ron, and Paola Antonelli. Ron Arad: No Discipline. New York: The Museum of Modern Art, 2009. Bazalgette, Peter. 'Independent Review of the Creative Industries'. Department for Digital, Culture, Media \& Sport, 22 September 2017. Accessed 5 August 2020. https://www.gov.uk/government/publications/ independent-review-of-the-creative-industries.

Chettiparamb, Angelique. Interdisciplinarity: A Literature Review. Southampton, UK: HEA Interdisciplinary Teaching and Learning Group, 2007. Accessed 5 August 2020. https://www. heacademy.ac.uk/system/files/interdisciplinarity_literature_review.pdf.

Choi, Bernard C., and Anita W. Pak. 'Multidisciplinarity, Interdisciplinarity and Transdisciplinarity in Health Research, Services, Education and Policy: 1. Definitions, objectives, and evidence of effectiveness'. Clinical and Investigative Medicine 29, no. 6 (2006): 351-64. [PubMed]

Coles, Alex. The Transdisciplinary Studio. Berlin: Sternberg Press, 2012.

Creative Industries Council. 'The UK Design Industry - An Overview'. Accessed 5 August 2020. http://www.thecreativeindustries.co.uk/industries/design/design-facts-and-figures.

Creative Industries Federation. 'Creative Education Agenda'. Accessed 5 August 2020. https://www. creativeindustriesfederation.com/sites/default/files/2017-05/CIF_EduAgenda_spreads.pdf.

Dawood, Sarah. 'Assemble: When We Sign Up to Something, We're Making a Commitment to See It Through'. Design Week, 22 April 2016. Accessed 5 August 2020. https://www.designweek.co.uk/issues/18-24-april-2016/assemble-when-we-sign-up-forsomething-were-making-a-personal-commitment-to-see-it-through.

Denscombe, Martyn. The Good Research Guide: For Small-scale Social Research Projects. Maidenhead, UK: Open University Press, 2010.

Dorst, Kees. Frame Innovation: Create New Thinking by Design, Cambridge, MA: MIT Press, 2015.

Eckert, Jan. 'The Y-Shaped Designer: Connective Competences as Key to Collaboration across Disciplines'. Journal of Education and Learning 6, no. 4 (2017): 137. [CrossRef]

Emerson, Robert M., Rachel I. Fretz, and Linda L. Shaw. Writing Ethnographic Fieldnotes. Chicago: University of Chicago Press, 2011.

Findeli, Alain. 'Rethinking Design Education for the 21st Century: Theoretical, Methodological, and Ethical Discussion'. Design Issues 17, no. 1 (2001). [CrossRef]

Friedman, Dan. Dan Friedman: Radical Modernism. New Haven, CT: Yale University Press, 1994. 
Friedman, Ken. 'Models of Design: Envisioning a Future Design Education'. Visible Language 46, no. 1 (2012): 132-53.

Furniss, Lara. 'Beyond Discipline: Design Practice and Design Education in the 21st Century'. September 2015. Accessed 5 August 2020. http://files.cargocollective.com/649648/BeyondDiscipline_web.pdf.

Garner, Richard. 'Finland Schools: Subjects Scrapped and Replaced with Topics as Country Reforms Its Education'. Independent, 20 March 2015. Accessed 5 August 2020. https://www.independent.co.uk/news/world/europe/finland-schools-subjects-are-out-and-topicsare-in-as-country-reforms-its-education-system-10123911.html.

Gray, Alex. 'The Ten Skills You Need to Thrive in the Fourth Industrial Revolution'. World Economic Forum, 19 January 2016. Accessed 5 August 2020. https://www.weforum.org/agenda/2016/01/the10-skills-you-need-to-thrive-in-the-fourth-industrial-revolution/.

Heatherwick, Thomas. Making. London: Thames and Hudson, 2012.

HESA. 'Higher Education Student Statistics: UK, 2016/2017 - Subjects Studied'. 11 January 2018. Accessed 5 August 2020. https://www.hesa.ac.uk/news/11-01-2018/sfr247-higher-education-studentstatistics.

Ivanauskas, Giedrius. 'Interview with Felix Barrett and Maxine Doyle Co-directors of the Drowned Man: A Hollywood Fable'. Made in Shoreditch, 3 July 2015. Accessed 5 August 2020. http://madeinshoreditch.co.uk/2015/07/03/interview-with-felix-barrett-and-maxine-doyleco-directors-of-the-drowned-man-a-hollywood-fable/.

Johnes, Rebecca. 'Education Policy Institute: Entries to Arts Subjects at Key Stage 4'. Education Policy Institute, 21 September 2017. Accessed 5 August 2020. https://epi.org.uk/publications-and-research/ entries-arts-subjects-key-stage-4/.

Korvenmaa, Pekka. 'Finland, Design and National Policies of Innovation'. Designophy, 20 March 2017. Accessed 5 August 2020. http://www.designophy.com/article/design-article-1000000023-finland. design-and-national-policies-of-innovation.htm.

Krznaric, Roman. How to Find Fulfilling Work. New York: Picador, 2012.

Kvale, Steinar, and Svend Brinkmann. InterViews: Learning the Craft of Qualitative Research Interviewing, 2nd ed. London: SAGE Publications, 2009.

Lerner, Fern. 'Foundations for Design Education: Continuing the Bauhaus Vorkurs Vision'. Studies in Art Education 46, no. 3 (2005): 211-26. [CrossRef]

Marshall, Catherine, and Gretchen B. Rossmann. Designing Qualitative Research. Newbury Park, CA: SAGE Publications, 2010.

Max-Neef, Manfred A. 'Foundations of Transdisciplinarity'. Ecological Economics 53, no. 1 (2005): 5-16. [CrossRef]

Ministry of Education and Culture Finland. 'Design Finland Programme'. Accessed 5 August 2020. tem.fi/documents/1410877/2901871/Design+Finland+Programme/8603cb0b-52ce-4025-b2080ad65e353b43.

Moholy-Nagy, Laszlo. Vision in Motion. Chicago: P. Theobald, 1947.

Nicolescu, Basarab. 'Transdisciplinarity: Past, Present and Future.'. In Moving Worldviews: Reshaping Sciences, Policies and Practices for Endogenous Sustainable Development, edited by Bertus Haverkort and Coen Reijntjes, 142-66. Leusden, the Netherlands: COMPAS, 2006. Accessed 5 August 2020. http://cetrans.com.br/assets/textos/transdisciplinarity-past-present-and-future.pdf.

Rawsthorn, Alice. Hello World: Where Design Meets Life. London: Penguin, 2013.

Robinson, Ken. The Element: How Finding Your Passion Changes Everything. London: Penguin, 2009.

Robinson, Ken, and Lou Aronica. Creative Schools: Revolutionizing Education from the Ground Up. London: Penguin, 2015.

Root-Bernstein, R. 'Multiple Giftedness in Adults: The Case of Polymaths'. In International Handbook on Giftedness, edited by Larisa Shavinina, 853-70. Dordrecht, the Netherlands: Springer, 2009.

Sanders, Elizabeth B.-N., and Pieter J. Stappers. 'Co-creation and the New Landscapes of Design'. Co-design 4, no. 1 (2008): 5-18. [CrossRef] 
Seymour, Richard. 'Recruitment: Heads or Tails'. Design Week, 7 September 2006. Accessed 5 August 2020. https://www.designweek.co.uk/issues/7-september-2006/seymour-warns-of-split-inprofession/.

Staley, David. 'The Future of the University: Speculative Design for Innovation in Higher Education'. Educause Review, 9 November 2015. Accessed 21 January 2019. https://er.educause.edu/articles/ 2015/11/the-future-of-the-university-speculative-design-for-innovation-in-higher-education.

Whicher, Anna. 'Reflections on Design Action Plans'. Accessed 5 August 2020. http://pdronline.co.uk/ blog/2017/07/reflections-on-design-action-plans.

Williams, Gareth. 21 Twenty-One: 21 Designers for Twenty-First Century Britain. London: V\&A Publishing, 2012. 